\title{
Tumor bed brachytherapy for locally advanced laryngeal cancer: a feasibility assessment of combination with ferromagnetic hyperthermia
}

\author{
Paul R. Stauffer \\ Thomas Jefferson University \\ Ilya L. Vasilchenko \\ Regional Clinical Cancer Center, Kemerovo, Russia \\ Aleksey M. Osintsev \\ Kemerovo Institute of Food Science and Technology \\ Dario B. Rodrigues

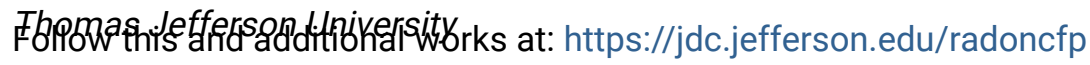 \\ ielaitaoBareAdchcology Commons \\ Themas isfeferso Uwiversitw access to this document benefits you
}

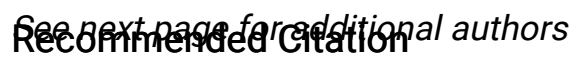

Stauffer, Paul R.; Vasilchenko, Ilya L.; Osintsev, Aleksey M.; Rodrigues, Dario B.; Bar-Ad, Voichita; Hurwitz, Mark; and Kolomiets, Sergey A., "Tumor bed brachytherapy for locally advanced laryngeal cancer: a feasibility assessment of combination with ferromagnetic hyperthermia" (2016). Department of Radiation Oncology Faculty Papers. Paper 85.

https://jdc.jefferson.edu/radoncfp/85

This Article is brought to you for free and open access by the Jefferson Digital Commons. The Jefferson Digital Commons is a service of Thomas Jefferson University's Center for Teaching and Learning (CTL). The Commons is a showcase for Jefferson books and journals, peer-reviewed scholarly publications, unique historical collections from the University archives, and teaching tools. The Jefferson Digital Commons allows researchers and interested readers anywhere in the world to learn about and keep up to date with Jefferson scholarship. This article has been accepted for inclusion in Department of Radiation Oncology Faculty Papers by an authorized administrator of the Jefferson Digital Commons. For more information, please contact: JeffersonDigitalCommons@jefferson.edu. 


\section{Authors}

Paul R. Stauffer, Ilya L. Vasilchenko, Aleksey M. Osintsev, Dario B. Rodrigues, Voichita Bar-Ad, Mark Hurwitz, and Sergey A. Kolomiets 
Tumor bed brachytherapy for locally advanced laryngeal cancer: A feasibility assessment of combination with ferromagnetic hyperthermia

\author{
Paul R. Stauffer ${ }^{1}$, Ilya L. Vasilchenko², Aleksey M. Osintsev ${ }^{3}$, \\ Dario B. Rodrigues ${ }^{1}$, Voichita Bar-Ad ${ }^{1}$, Mark D. Hurwitz ${ }^{1}$, and Sergey A. Kolomiets ${ }^{2}$
}

${ }^{1}$ Thomas Jefferson University, Philadelphia PA, USA

${ }^{2}$ Regional Clinical Cancer Center, Kemerovo, Russia

${ }^{3}$ Kemerovo Institute of Food Science and Technology, Kemerovo, Russia

Corresponding author:

Paul R. Stauffer

Professor and Director of Thermal Oncology Physics

Thomas Jefferson University

Radiation Oncology Department

Bodine Cancer Center Room G302A

111 S. 11th. St.

Philadelphia PA 19107

215-503-8825

paul.stauffer@jefferson.edu

Running title: Tumor bed implant for multimodal therapy 


\begin{abstract}
Purpose: To assess the feasibility of adding hyperthermia to an original method of organpreserving brachytherapy treatment for locally advanced head and neck tumors.

Methods and Materials: The method involves organ-preserving tumor resection and adjunctive high-dose-rate (HDR) brachytherapy delivered via afterloading catheters. These catheters are embedded in a polymeric implant prepared intraoperatively to fill the resection cavity, allowing precise computer planning of dose distribution in the surrounding at-risk tumor bed tissue. Theoretical and experimental analyses address the feasibility of heating the tumor bed implant by coupling energy from a $100 \mathrm{kHz}$ magnetic field applied externally into ferromagnetic particles, which are uniformly distributed within the implant. The goal is to combine adjuvant hyperthermia $\left(40-45^{\circ} \mathrm{C}\right)$ to at-risk tissue within $5 \mathrm{~mm}$ of the resection cavity for thermal enhancement of radiation and chemotherapy response.

Results: A five-year relapse free survival rate of $95.8 \%$ was obtained for a select group of 48 male patients with T3N0M0 larynx tumors, when combining organ-preserving surgery with HDR brachytherapy from a tumor bed implant. Anticipating the need for additional treatment in patients with more advanced disease, a theoretical analysis demonstrates the ability to heat at-risk tissue up to $10 \mathrm{~mm}$ from the surface of an implant filled with magnetically coupled ferromagnetic balls. Using a laboratory induction heating system, it takes just over 2 minutes to increase the target tissue temperature by $10^{\circ} \mathrm{C}$ using a $19 \%$ volume fraction of ferromagnetic spheres in a $2 \mathrm{~cm}$ diameter silicone implant.
\end{abstract}

Conclusion: The promising clinical results of a 48 patient pilot study demonstrate the feasibility of a new organ sparing treatment for laryngeal cancer. Anticipating the need for additional therapy, theoretical estimations of potential implant heating are confirmed with laboratory experiments, preparing the way for future implementation of a thermobrachytherapy implant approach for organsparing treatment of locally advanced laryngeal cancer.

Keywords: locally advanced head and neck tumors, laryngeal cancer, organ-preserving surgery, HDR brachytherapy, intraoperative hyperthermia. 


\section{Introduction}

Laryngeal cancer comprises about 3\% of all human cancers. The disease occurs primarily in 4060 year old males. Effective treatment of laryngeal cancer depends heavily on early detection. However, initial tumor growth often occurs without being noticed, especially for endophytic nodules. This explains typical late referral for medical help that leads to more than $50 \%$ of patients having stage $\mathrm{T} 3$ and $\mathrm{T} 4$ primaries. The most common treatment for such patients is total laryngectomy, which inevitably leads to traumatic disability without ruling out tumor recurrence. Ongoing progress in multimodality approaches to treat laryngeal cancer (Holsinger, 2008) have led to five-year survival rates above $90 \%$ for early detected T1-T2 stage tumors. However, five-year survival is $<60 \%$ for patients with intermediate or advanced stage disease (Rudolph et al., 2011), which highlights the need for improved therapy.

Integration of new treatment approaches such as organ preservation surgery (Sperry et al., 2013, Wilkie et al., 2015, Vasil'chenko et al., 2011), HDR brachytherapy (Obinata et al., 2007), and hyperthermia (Paulides et al., 2007a, Paulides et al., 2010, Falk and Issels, 2001) have been proposed to improve quality of life in advanced head and neck cases by saving larynx function as well as increasing survival. Local tumor hyperthermia (temperatures of $40-45^{\circ} \mathrm{C}$ ) is a promising adjuvant treatment method in cancer therapy, contributing to a significant improvement of therapeutic efficacy in sites where adequate heating is possible (Overgaard et al., 1996, Sneed et al., 1998, Valdagni and Amichetti, 1994, Datta et al., 2016b, Datta et al., 2016a, Issels et al., 2010). This technique is normally applied as an adjuvant to established cancer treatment modalities such as radiotherapy and chemotherapy (Hurwitz and Stauffer, 2014, Dewhirst et al., 2015).

Depending on size and location in the body, there are many different technologies available for heating tumors. Local hyperthermia induced by microwave radiation is often used for treatment of tumors close to the skin surface, but penetration of effective heating is limited to about $3-4 \mathrm{~cm}$. Treatment of tumors deep in the neck with external microwave waveguide applicators has been reported, but significant heating of overlying tissues is unavoidable (Kouloulias et al., 2014, Amichetti et al., 1993). Penetration deeper in tissue using a phased array of microwave antennas has been proposed (Arcangeli et al., 1984, Gross et al., 1990) and prototype arrays designed specifically for neck tumors are currently under development (Paulides et al., 2007b, Paulides et al., 2010, Togni et al., 2013). Radiofrequency phased-array systems are also available that can penetrate deep in the body, but the long wavelength generates a large heat focus (Canters et al., 2009, Van Rhoon et al., 2003, Fatehi and van Rhoon, 2008). In either case, significant heating of critical normal tissues outside the tumor target is usually unavoidable. Alternatively, the use of ultrasound from external transducer arrays allows precise focusing into deep tissue targets (Al-Bataineh et al., 2011, Chen et al., 2011, Haar and Coussios, 2007, Hurwitz et al., 2014, Tempany et al., 2011), but this 
approach is problematic for larynx due to the heterogeneous anatomy and proximity to air and bone regions, which reflect or absorb ultrasound preferentially. Thus, the complex anatomy and sensitivity of surrounding critical normal tissues severely restricts the application of external heating technology to small head and neck tumors.

Several interstitial implant techniques allow focused heating at depth, including interstitial radiofrequency electrodes, microwave antennas, ultrasound transducers, and several hot source techniques based on thermal conduction (Stauffer et al., 1995). Most of these modalities require percutaneous insertion of an array of needles or catheters to insert heat sources, power connections, and temperature control sensors. For most head and neck tumors, maintaining an externalized array of percutaneous catheters following surgery is painful and undesirable for the patient. One hot source technique that overcomes these issues is the use of external magnetic fields to couple energy non-invasively into implanted ferromagnetic needles or spheres (ferroseeds). This minimally invasive approach has been investigated by numerous groups beginning almost 45 years ago (Brezovich et al., 1984, Burton et al., 1971, Kobayashi et al., 1986, Stauffer et al., 1984a, Mack et al., 1993, Tucker et al., 2000, Stauffer et al., 1984b, Atkinson et al., 1984). When these 1-2 mm diameter ferromagnetic materials are immersed in a sub-megahertz radiofrequency magnetic field, eddy currents are induced on the metal surface. As a result, the implants are heated by resistive losses from the induced currents, and tissue around the implants is heated by thermal conduction from the hot surface. Because of the rapid falloff of temperature away from small diameter heat sources, there are steep thermal gradients around the implants, especially in tissue with high blood perfusion. Tissue immediately adjacent to the heat sources is generally overheated, while tissue $>5$ $\mathrm{mm}$ from the implants may not be heated sufficiently (Chin and Stauffer, 1991).

One of the proposed ways to improve local tumor control and survival rates for patients with locally advanced head and neck cancer is an original method of intraoperative HDR brachytherapy invented at the Regional Clinical Cancer Center (RCCC) in Kemerovo, Russia (Vasil'chenko et al., 2008, Vasil'chenko et al., 2011). This method combines laryngeal resection surgery with brachytherapy, where a patient-specific biocompatible implant mold is formed within the resection cavity, replacing tumor and providing precise computable locations for the HDR source. This paper reviews the results of a clinical study using this method for treatment of 48 patients with laryngeal cancer. With the goal of expanding this novel treatment to larger numbers of patients with more advanced disease, we assessed the feasibility of adding hyperthermia to further enhance clinical outcomes, by incorporating spherical ferroseeds into the same tumor bed implant and coupling heat into the seeds via an externally applied magnetic induction field (Osintsev et al., 2013, Vasil'chenko et al., 2013). 


\section{Methods}

\section{Surgery and Brachytherapy}

Between September 2006 and June 2009, a total of 96 male patients with stage T3N0M0 laryngeal cancer were treated at the RCCC with a novel technique. All patients signed voluntary consent according the Fundamentals of Russian legislation on health care N5487-1 for treatment under a protocol approved by the Ethics Committee at the Russian Center for Research in Radiological and Surgical Technologies (St. Petersburg, Russia). All patients received external beam radiotherapy using two lateral opposed fields measuring $6-8 \times 8-12 \mathrm{~cm}^{2}$. The area inside the $90 \%$ isodose line included the larynx and potential microscopic tumor extension. A total external beam dose of $35 \mathrm{~Gy}$ was delivered using $2.5 \mathrm{~Gy} /$ fraction, 5 times a week. Radiation therapy was supplemented with concurrent administration of 5-fluorouracil (5-FU) as a radiosensitizer at a dose of $250 \mathrm{mg} / \mathrm{m}^{2}$ intravenous, every other day.

Initial tumor response was assessed 14 days after completion of external beam radiotherapy and 5-FU administration, when acute radiation reactions had abated. From the initial group of 96 men, 48 patients $(50.0 \%)$ had obvious reduction of tumor volume and were selected to continue with the protocol. From this selected favorable patient group, keratinizing squamous cell carcinoma of the larynx was observed in 41 patients $(85.4 \%)$ and non-keratinizing cancer in 7 patients (14.6\%). With respect to tumor location, cancer of the glottis part of the larynx was most common (62.5\%), followed by cancer of the supraglottic larynx (25\%), and similar involvement of two adjacent parts of the larynx (12.5\%). Exophytic tumor growth was noted in 7 patients (14.6\%), infiltrative in 21 patients $(43.7 \%)$ and mixed in 20 patients (41.7\%). All responding patients underwent organpreservation surgery including different variants of partial larynx resection that depended on tumor response. At the time of surgery, a custom implant was fabricated from soft pliable silicone material that hardened in situ to fit the size and shape of the resection cavity (figure 1).

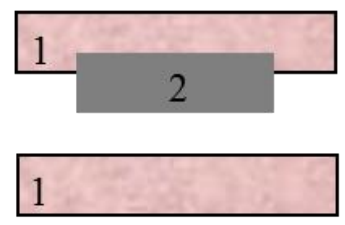

(a)

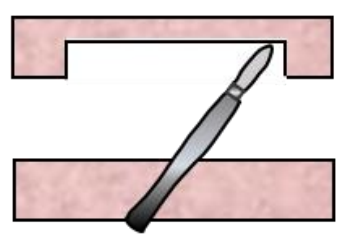

(b)

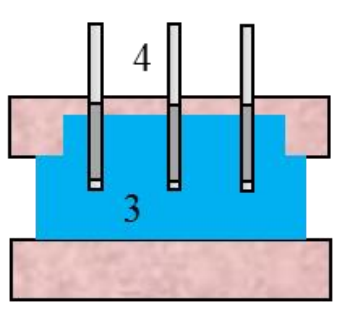

(c)

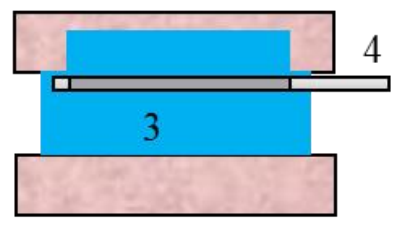

(d)

Figure 1. Schematic of organ-preserving surgery and preparation for brachytherapy treatment: (a) larynx with tumor; (b) partially resected larynx; (c) inserted volumetric implant mold with lateral afterloading catheters; and (4) inserted longitudinal catheter. 1 - larynx walls; 2 - tumor; 3 - implant mold; 4 afterloading catheters (active part marked in dark grey).

Figure 1 gives a pictorial of the surgical procedure. Following placement of a tracheostoma, the exposed tumor is excised. After wound hemostasis, a 3D volumetric implant is created by filling the 
resected tumor bed (and part of the larynx) with flexible silicone-based polymeric putty (Speedex, Coltene Inc, Cuyahoga Falls $\mathrm{OH}$ ) that is pressed into place by the surgeon. Polymerization typically generates a brief mild $<2{ }^{\circ} \mathrm{C}$ exothermic reaction. The mass becomes firm enough in about 3 minutes to hold its shape, while remaining pliable enough to insert the brachytherapy catheters and a retraction string fastener, which enables the removal of the implant through the mouth at the end of therapy. The solidified implant is then removed and catheters inserted into the mold, in positions appropriate for guiding radioactive seeds to deliver brachytherapy to the tumor bed (figure 2a-b). Ideal catheter configuration depends on size, shape and location of the tumor bed implant which is optimized in the OR based on experience of the surgeon and radiotherapist. An axially directed flexible catheter is least traumatic as it can be withdrawn after treatment through the tracheostoma. Additional semi-rigid catheters exiting through the surgical scar are added as needed to improve dose uniformity. Dosimetric planning is used to optimize the number and spacing of catheters and source locations. The active length of each implant catheter is customized to irradiate at-risk tissues around the resected tumor and minimize dose to surrounding organs-at-risk. The equivalence of radiation delivery through the silicone implant material is confirmed by dosimetric measurements. The pre-formed implant is then reinserted into the resected tumor bed, and the wound is sutured closed around the percutaneous catheters (figure $2 \mathrm{c}$ ).
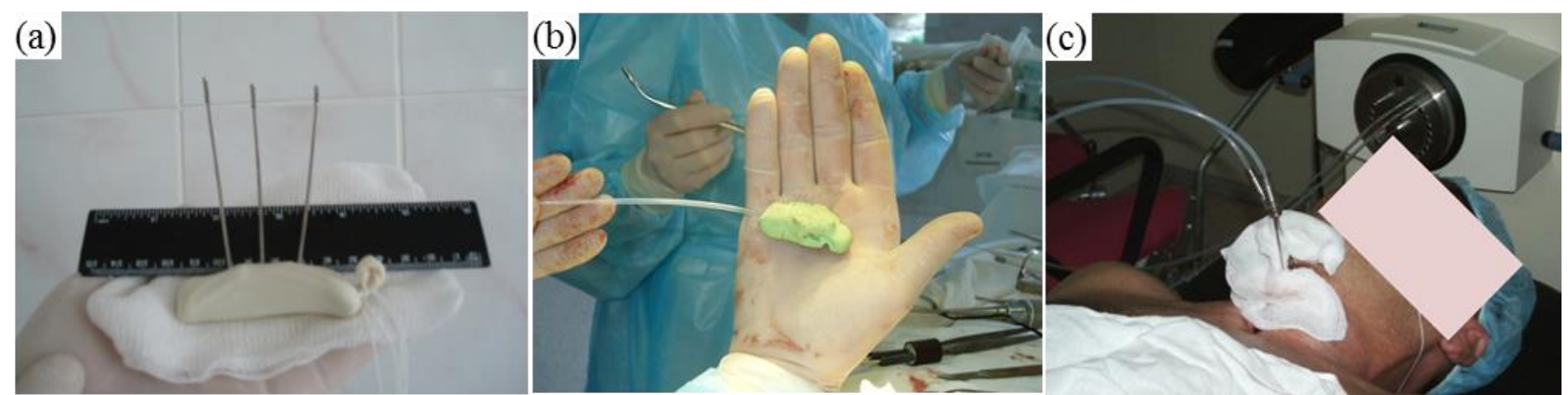

Figure 2. Patient-specific biocompatible implant with (a) rigid lateral catheters and (b) flexible longitudinal catheter. (c) Brachytherapy delivery with catheters connected to an HDR brachytherapy system.

After radiographic imaging of the implant, computer-assisted 3D reconstruction software is used to segment the implant, gross tumor volume (GTV), clinical target volume (CTV), and surrounding neck structures including organs at risk (figure 3). The resulting images are transmitted to the HDR planning program through a projection scanner. The planning target volume includes the resected tumor bed with a margin of $\sim 5 \mathrm{~mm}$ around the implant.

A single dose of $10 \mathrm{~Gy}$ minimum to the implant/tissue interface is delivered immediately after surgery (usually within one hour) by means of the GammaMed Plus ${ }^{\mathrm{TM}}$ brachytherapy apparatus, and then the catheters are removed from the implant. Following delivery of radiation, the implant is left in place mainly as an obturator to avoid negative post-operative and post-radiation reactions 
such as larynx stenosis. Fourteen days after surgery, the implant is removed from the lumen of the larynx through the mouth by pulling on the retraction string fastened to the implant.

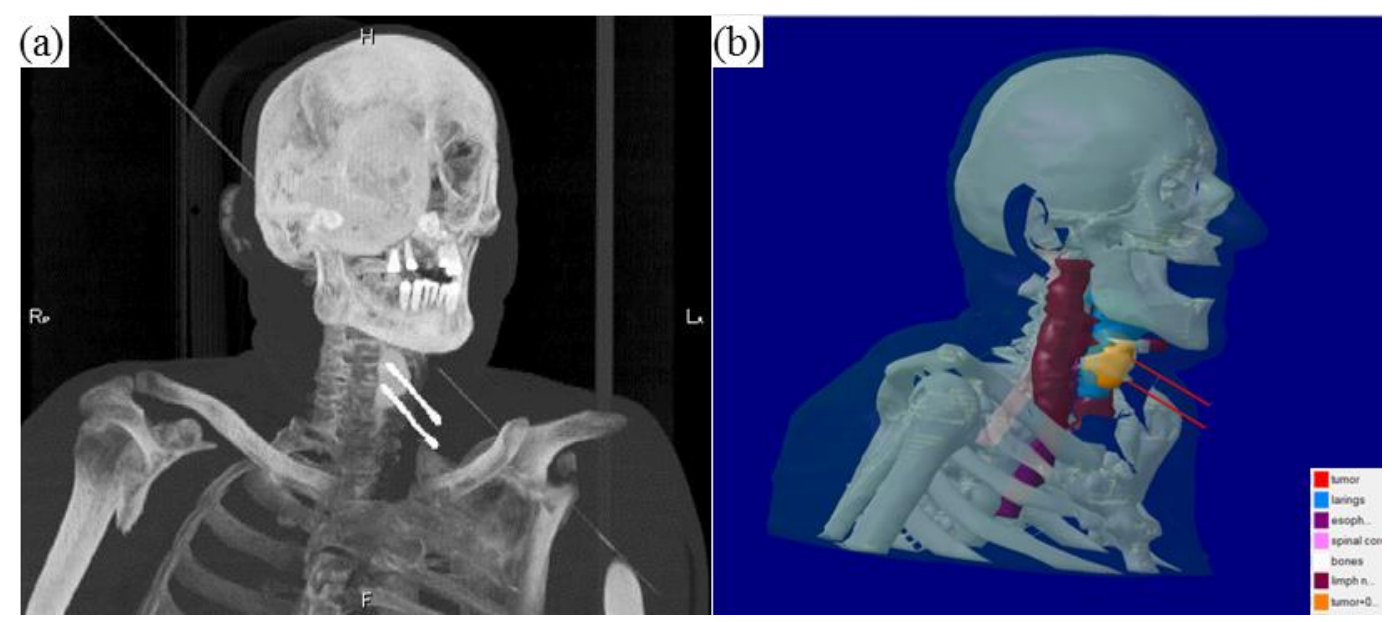

Figure 3. (a) 3D reconstructed image of patient with two catheter implant mold surgically placed in partially resected larynx; (b) Segmented 3D image used for HDR treatment planning showing target volume (yellow) with two brachytherapy catheters and critical normal tissue structures to avoid.

Treatment efficacy is assessed by the following criteria: (1) degree of recovery of laryngeal function in terms of swallowing, breathing and speech; (2) incidence and character of postoperative complications; and (3) duration of disease-free period after treatment. The nasogastric tube removal and patient's ability to take adequate oral nutrition are indications of the recovery of laryngeal function, including effective separation of breathing and swallowing. The rehabilitation of breathing is characterized by the time of decannulation after the multimodality treatment.

\section{Hyperthermia feasibility}

In order to enhance clinical responses in patients with more advanced head and neck cancers, we investigated the feasibility of adding local hyperthermia. For optimum compatibility with the brachytherapy implant approach, we choose the magnetic induction heating technique because it eliminates the need for power or thermal probe connections to the implant. In this method, ferromagnetic balls are embedded in the implant and heated inductively using an externally applied $100 \mathrm{kHz}$ magnetic field (figure 4). The raw silicone implant material has a soft putty-like consistency prior to polymerization and once properly mixed, the ferromagnetic particles are distributed uniformly throughout the material. Since the implant solidifies quickly in situ or following a short heat exposure, no sedimentation or separation of the embedded ferromagnetic particles occurs even during subsequent heating. Thus, the ferromagnetic particles remain uniformly distributed throughout the implant mold and thereby produce uniform temperature of the implant surface, unlike needle or catheter based interstitial heating technologies that generate very hot and cold regions between heat sources. 
For initial laboratory testing of this approach, we chose stainless steel balls of $1 \mathrm{~mm}$ diameter as ferromagnetic particles dispersed throughout a spherically shaped silicone mold with $2 \mathrm{~cm}$ diameter. This laboratory implant was inserted at the center of an air core induction coil with 10 turns, $5 \mathrm{~cm}$ diameter, and $8 \mathrm{~cm}$ axial length. With $20 \mathrm{~W}$ of power applied at $100 \mathrm{kHz}$, a magnetic field of $500 \mathrm{~A} / \mathrm{m}$ was obtained in the region of the ferromagnetic seed filled polymeric mass. Temperatures were measured at the implant center with Type E thermocouples (chromelconstantan) with $0.1 \mathrm{~mm}$ diameter wires aligned perpendicular to the field. RF shielding of the thermocouple wires was provided by thin grounded aluminum tubes, allowing essentially artifact free thermometry in the $500 \mathrm{~A} / \mathrm{m}$ field.

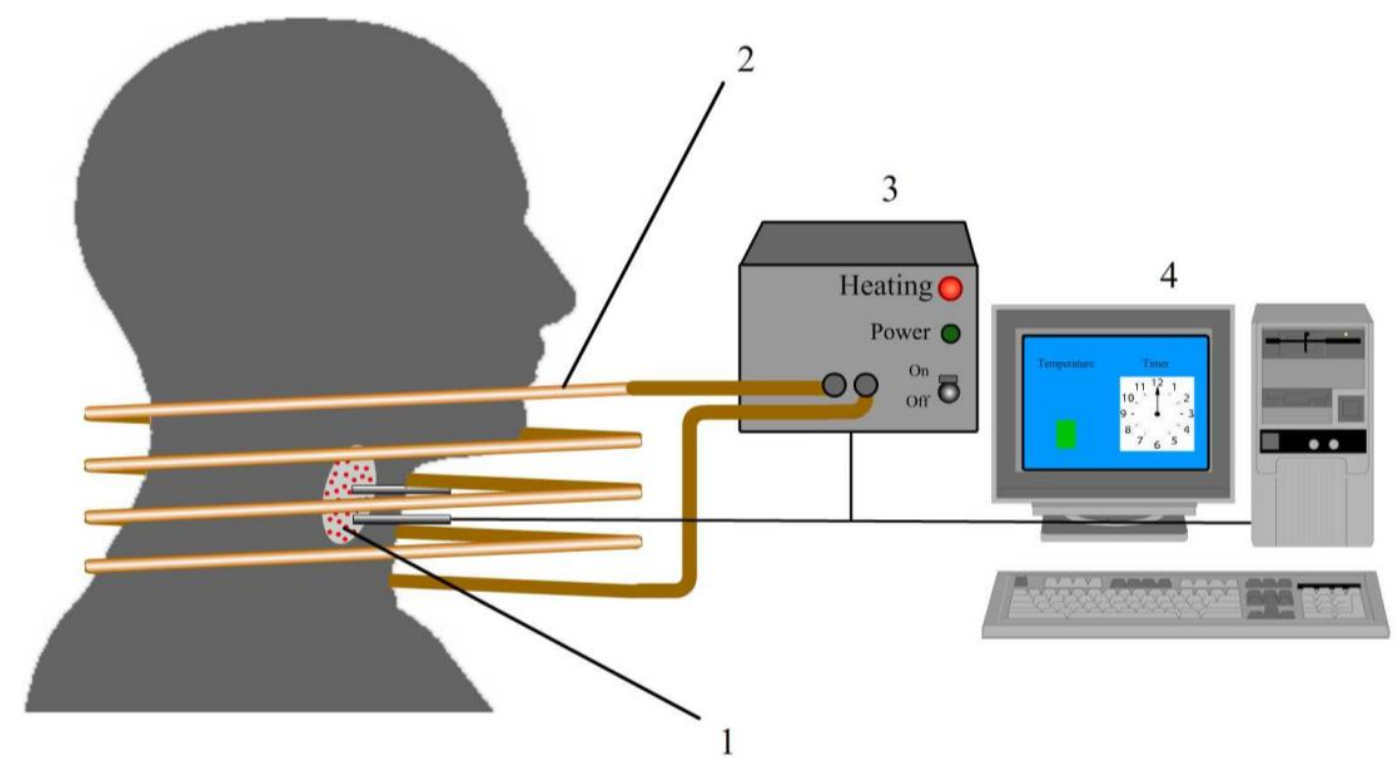

Figure 4. Schematic of magnetic induction heating procedure. 1 - Modified implant with ferromagnetic material dispersed uniformly throughout the silicone implant alongside brachytherapy catheters; 2 induction coil to generate magnetic field; $3-\mathrm{RF}$ power generator $(\sim 100 \mathrm{kHz}) ; 4-$ computer controller.

To estimate the heating characteristics of this method, we consider a simple model of a spherical implant mold with radius $R_{i}=1 \mathrm{~cm}$, in which the conductive ferromagnetic spherical particles of radius $R_{S}$ are uniformly distributed. For an implant in a magnetic field of amplitude $H_{m}$ and frequency $\omega$, heat is produced in each sphere due to induced eddy currents. Provided $R_{S}<<R_{i}$ and sufficiently high density of conductive ferromagnetic particles, the steady state temperature distribution inside the implant $\left(T_{i}\right)$ and in the tissue around the implant $\left(T_{t}\right)$ are described by the heat equation and Pennes' equation (Pennes, 1948), respectively:

$$
\begin{gathered}
k_{i} \nabla^{2} T_{i}+Q_{i}=0, \\
k_{t} \nabla^{2} T_{t}-\omega_{b t} c_{b}\left(T_{t}-T_{a}\right)+m_{t}=0,
\end{gathered}
$$

where $k$ is thermal conductivity; $Q$ is the heat generated by the inductively coupled ferromagnetic spheres (in $\mathrm{W} / \mathrm{m}^{3}$ ) assumed to be homogenously distributed within the implant; $\omega_{b}$ is blood 
perfusion rate of surrounding tissue (in $\left.\mathrm{kg} / \mathrm{s} / \mathrm{m}^{3}\right) ; c_{b}$ is specific heat capacity of blood $(3617 \mathrm{~J} / \mathrm{kg} / \mathrm{K}$ ); $T_{a}$ is arterial temperature $\left(37^{\circ} \mathrm{C}\right) ; m$ is the heat generated in tissue due to metabolism $\left(\mathrm{in} \mathrm{W} / \mathrm{m}^{3}\right)$; and the indexes $i$ and $t$ correspond to the polymeric implant and tissue, respectively.

Equations (1) and (2) can be solved directly considering the following boundary conditions: finite temperature at the implant center $\left(\partial T_{i} / \partial r=0\right.$ at $\left.r=0\right)$; temperature and heat flux continuity at the implant/tissue interface $R_{i} ; T_{t}=T_{0}$ at a distance $R_{\text {ext }}$ sufficiently distant to be unaffected by the implant heat source (e.g. several centimeters), and body core temperature $T_{0}=37^{\circ} \mathrm{C}$. The solution of equation (2) has been derived previously for these boundary conditions (Rodrigues et al., 2013). Applying this to the current problem, the analytical solution for temperature distribution inside the implant and in tissue around the implant may be estimated to first order considering no blood perfusion or metabolism. Using a spherical coordinate system, the solution yields:

$$
\begin{gathered}
T_{i}(r)=-\frac{Q_{i}}{6 k_{i}} r^{2}+\frac{Q_{i} R_{i}^{3}}{6 k_{i} k_{t}} \frac{2 k_{i}\left(R_{e x t}-R_{i}\right)+R_{e x t} k_{t}}{R_{i} R_{e x t}}+T_{0}, \text { and } \\
T_{t}(r)=\frac{Q_{i} R_{i}^{3}}{3 k_{t}}\left(\frac{1}{r}-\frac{1}{R_{e x t}}\right)+T_{0} .
\end{gathered}
$$

To achieve therapeutic radiosensitization from moderate temperature hyperthermia, temperature in the at-risk tissue target should be in the range $40-45^{\circ} \mathrm{C}$ (Dewhirst et al., 2015). This is achieved by imposing a temperature of $45^{\circ} \mathrm{C}$ at the interface between the implant and tissue, which will heat the surrounding tissue target by thermal conduction. Using equation (4) and the latter condition, i.e. $T_{i}\left(R_{i}\right)=45^{\circ} \mathrm{C}$, the heating power in Watts $P_{i}=Q_{i} \cdot V_{i}$ (with $V_{i}$ the implant volume) required from within the implant to heat the surrounding at-risk tissue is:

$$
P_{i}=\frac{24 k_{t} R_{e x t} V_{i}}{R_{0}^{2}\left(R_{e x t}-R_{0}\right)}
$$

where we use $T_{0}=37^{\circ} \mathrm{C}$ as core temperature.

The tumor bed tissue is not homogeneous however. The implant in neck is surrounded by heterogeneous tissue that includes low perfusion tissues such as fat and bone $\left(\omega_{b} \sim 0.3 \mathrm{~kg} / \mathrm{s} / \mathrm{m}^{3}\right)$ and higher perfusion tissues such as muscle $\left(\omega_{b} \sim 0.7 \mathrm{~kg} / \mathrm{s} / \mathrm{m}^{3}\right)$. In addition, heating the tumor bed $>40^{\circ} \mathrm{C}$ will increase blood perfusion eight-fold or more, reaching over $6 \mathrm{~kg} / \mathrm{s} / \mathrm{m}^{3}$ in heated muscle (Sekins et al., 1984, Hasgall et al., January 13th, 2015). In order to bracket the range of expected heating profiles, we determine the temperature for a range of blood perfusion scenarios: $\omega_{b}=0$ $\mathrm{kg} / \mathrm{s} / \mathrm{m}^{3}$ using equation (3); $\omega_{b}=0.7 \mathrm{~kg} / \mathrm{s} / \mathrm{m}^{3}$ (basal perfusion); and $\omega_{b}=6 \mathrm{~kg} / \mathrm{s} / \mathrm{m}^{3}$ (active perfusion) using the analytical solution derived by Rodrigues et al. (Rodrigues et al., 2013). In addition, we determine the therapeutic penetration depth, defined by the distance into tumor bed where $T_{t} \geq 40^{\circ} \mathrm{C}$. 
The amplitude of the magnetic field $\left(H_{m}\right)$ required to produce the required amount of heat from the implant is a function of the heat generated by eddy currents in each steel ball, defined here as $P_{s}$ $=Q_{i} V_{s} / v$ (in Watts) with $V_{s}$ being the volume of each steel ball of radius $R_{s}$ and $v$ being the volume fraction of steel inside the implant mold of radius $R_{i}$. The magnetic field amplitude can then be determined (Stauffer et al., 1984b):

$$
H_{m}=\sqrt{\frac{P_{s}}{3 \pi R_{s}^{2} \sqrt{2 \omega \mu_{0} \mu / \sigma}}}
$$

where $\sigma$ is electrical conductivity, $\mu$ is a magnetic permeability, $\mu_{0}=4 \pi \cdot 10^{-7} \mathrm{H} / \mathrm{m}, \omega=2 \pi f$ and $f$ is magnetic field frequency.

\section{Results}

\section{Surgery and Brachytherapy}

Treatment with this technique was well tolerated as previously reported. The nasogastric tube was removed within 2 days in all 48 patients. Proper laryngeal function was preserved entirely in 44 patients $(91.7 \%)$. Four patients $(8.3 \%)$ were not able to swallow liquid food. In terms of breathing, 47 patients $(98 \%)$ were decannulated 2 to 6 months after completion of the laryngeal cancer treatment. One patient $(2.1 \%)$ developed cicatricial stenosis of the larynx and could not be decannulated, even after surgical treatment of his laryngeal stenosis. Reconstruction of tracheofistulas formed during healing of the tracheostomy was performed in 8 patients (16.7\%) within 6 months to 2 years. The 3-year relapse-free survival rate reported in 2011 was $95.8 \%$, i.e., 46 patients were alive with no evidence of local recurrence (Vasil'chenko et al., 2011). Disease progression occurred in 2 patients $(4.2 \%)$ within 6 months. These two patients underwent total laryngectomy with one dying of distant metastases. With an additional 24 months of follow-up, there were no additional cases of disease progression such that the 5-year relapse free survival rate was $95.8 \%$ (Vasil'chenko et al., 2013).

Figure 5 shows the isodose distributions within the planning target volume generated by the ABACUS planning system, with shaded regions overlaid to indicate the extent of implant and tumor bed tissue target. Typically, brachytherapy was planned to achieve a minimum target dose of $10 \mathrm{~Gy}$ at the implant border. Figure 5 demonstrates symmetric distribution of active points inside the implant. If the target volume around the implant is non-symmetric, as it is for example in figure 1, the surgeon will adjust position of the catheters appropriately and the radiotherapist will preplan the active points to ensure conformality of dose to the target region. Radiation preplanning is straightforward due to tissue-equivalence of the implant material for radiation. 

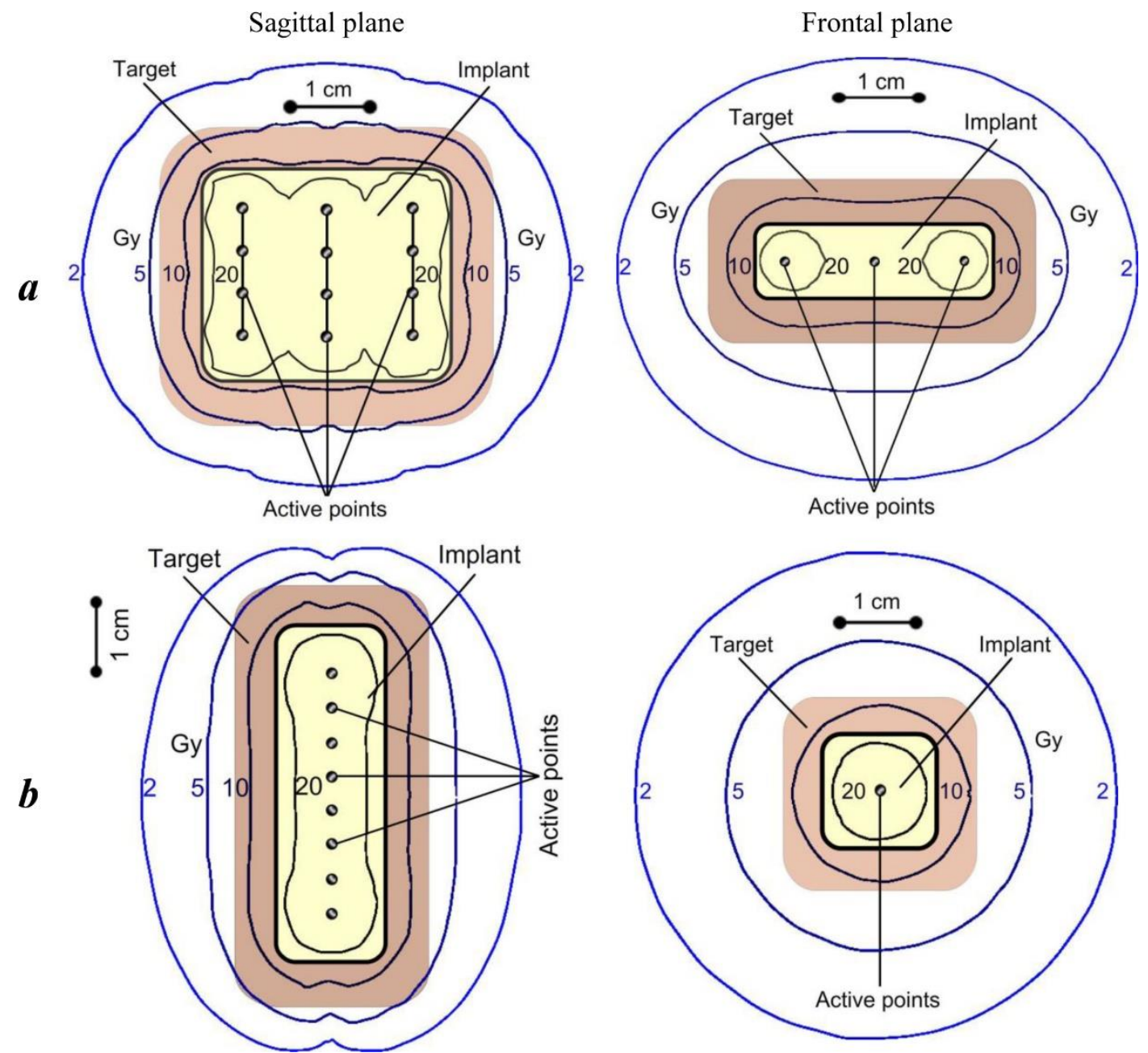

Figure 5. Isodose distribution from the lateral $(a)$ and longitudinal $(b)$ catheters.

\section{Hyperthermia feasibility}

The feasibility of adding hyperthermia via the brachytherapy implant was assessed theoretically and experimentally. For a $2 \mathrm{~cm}$ diameter spherical implant $\left(R_{i}=1 \mathrm{~cm}\right)$ placed in a tumor bed with thermal conductivity similar to muscle $\left(k_{t}=0.5 \mathrm{~W} / \mathrm{m} / \mathrm{K}\right)$ and surrounded by a $37^{\circ} \mathrm{C}$ tissue boundary at $R_{\text {ext }}=5 \mathrm{~cm}$, the power absorption within the implant required to heat the surrounding tumor bed may be calculated from equation (5) to be $P_{i}=0.6 \mathrm{~W}$, before considering the cooling effects of blood perfusion. The thermal conductivity of the implant is estimated to be $k_{i}=10.2 \mathrm{~W} / \mathrm{m} / \mathrm{K}$ for a volume fraction of metal spheres of $v=0.2$, as determined from the volume-weighted average of silicone $(0.2 \mathrm{~W} / \mathrm{m} / \mathrm{K})$ and steel $(50.2 \mathrm{~W} / \mathrm{m} / \mathrm{K})$. Accounting for the heat lost due to blood perfusion, the required power from the implant increases to $0.9 \mathrm{~W}$ for basal perfusion (resting muscle) and 1.6 $\mathrm{W}$ for active perfusion (highly-perfused soft tissue at elevated temperature). Figure 6a presents the expected temperature distribution in and around a $2 \mathrm{~cm}$ diameter implant heated to a surface temperature of $45^{\circ} \mathrm{C}$, for a bracketing range of tissue perfusion expected in the human neck. The penetration of therapeutic heating $\left(>40^{\circ} \mathrm{C}\right)$ extends out from the implant surface into surrounding tumor bed $10 \mathrm{~mm}$ if no perfusion, $6.1 \mathrm{~mm}$ with basal perfusion rate, and $3.2 \mathrm{~mm}$ with the 
anticipated upper limit active perfusion rate. Figure $6 \mathrm{~b}$ shows the implant surface temperatures required to obtain the minimum therapeutic temperature of $40^{\circ} \mathrm{C}$ throughout a $5 \mathrm{~mm}$ rim of tumor bed tissue for the same three perfusion levels. Table 1 gives a summary of calculations regarding the required implant power absorption from the magnetic field, as well as the resultant heating of tumor bed tissue for a bracketing range of possible tissue perfusion levels. At temperatures exceeding $45-48^{\circ} \mathrm{C}$, we can expect tissue damage to reduce blood perfusion below the high perfusion level shown in red in figure 6, which would decrease the implant surface temperature required to get $40^{\circ} \mathrm{C}$ throughout a $5 \mathrm{~mm}$ rim of target tissue.
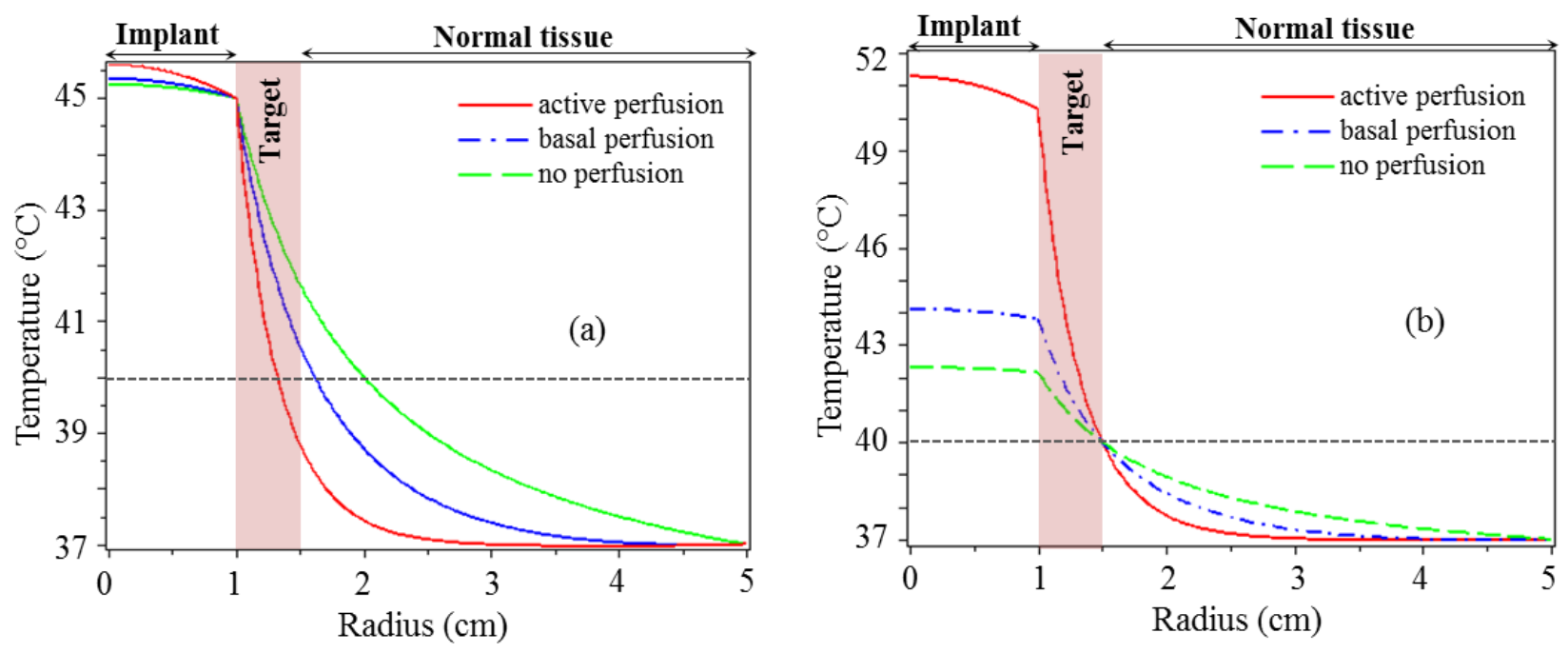

Figure. 6. Temperature profiles generated by a $2 \mathrm{~cm}$ diameter silicone implant with $1 \mathrm{~mm}$ diameter steel balls uniformly distributed with a volume fraction of 0.2 : (a) analytical solution of equation (4), where both blood perfusion and metabolic heat rate are set to zero; and two more cases with basal blood perfusion $(0.7$ $\left.\mathrm{kg} / \mathrm{s} / \mathrm{m}^{3}\right)$ and active blood perfusion $\left(6.2 \mathrm{~kg} / \mathrm{s} / \mathrm{m}^{3}\right)$ where $m_{t}=988 \mathrm{Wm}^{3}$; (b) theoretical penetration of heat around the implant, showing required implant surface temperatures to achieve minimum therapeutic tumor bed temperature of $40^{\circ} \mathrm{C}$ at $5 \mathrm{~mm}$ distance from implant for the three blood perfusion cases.

Using a volume fraction of steel balls of $v=0.2$, we estimate $N=v V_{i} / V_{s}=1600$ balls of $1 \mathrm{~mm}$ diameter in the $2 \mathrm{~cm}$ diameter spherical implant (volume $V_{i}=4.2 \mathrm{~cm}^{3}$ ). Assuming the steel balls are all in the same field conditions, then each ball must produce the same power absorption of $P_{s}=P_{i} / N$ $=2.5-16 \times 10^{-4} \mathrm{~W}$ per steel ball for the range of blood perfusion studied. Using equation (6) with $\sigma=$ $10^{7} \mathrm{~S} / \mathrm{m}, \mu=100$ at $f=100 \mathrm{kHz}$ and $R_{s}=0.5 \mathrm{~mm}$, we find the magnetic field amplitude required to generate that amount of heating ranges from $H_{m}=163-414 \mathrm{~A} / \mathrm{m}$ for the range of perfusion analyzed.

Table 1. Theoretical power deposition from ferromagnetic spheres within the tumor bed implant required to heat a surrounding $5 \mathrm{~mm}$ shell of at-risk tissue target to a minimum of $40^{\circ} \mathrm{C}$, for a bracketing range of perfusion levels.

\begin{tabular}{|c|c|c|c|c|c|}
\hline $\begin{array}{c}\text { Tissue Blood } \\
\text { Perfusion }\end{array}$ & $\begin{array}{c}\text { Temperature Range } \\
\text { in Tumor Bed }\end{array}$ & $\begin{array}{c}\text { Power Density } \\
\text { in Implant }\end{array}$ & $\begin{array}{c}\text { Power } \\
\text { Absorbed in } \\
\text { Implant }\end{array}$ & $\begin{array}{c}\text { Power } \\
\text { Absorbed in } \\
\text { each Sphere }\end{array}$ & $\begin{array}{c}\text { Required } \\
\text { Magnetic } \\
\text { Field }\end{array}$ \\
\hline$\omega_{b}\left(\mathrm{~kg} / \mathrm{s} / \mathrm{m}^{3}\right)$ & $T_{\text {target }}\left({ }^{\circ} \mathrm{C}\right)$ & $Q_{i}\left(\mathrm{~W} / \mathrm{m}^{3}\right)$ & $P_{i}(\mathrm{~W})$ & $P_{s}(\mathrm{~W})$ & $H_{m}(A / m)$ \\
\hline
\end{tabular}




\begin{tabular}{|c|c|c|c|c|c|c|}
\hline None & 0 & $40.0-42.1$ & $9.45 \times 10^{4}$ & 0.4 & $2.5 \times 10^{-4}$ & 163 \\
\hline Basal & 0.7 & $40.0-43.8$ & $1.80 \times 10^{5}$ & 0.8 & $4.7 \times 10^{-4}$ & 224 \\
\hline Active & 6.2 & $40.0-50.3$ & $6.14 \times 10^{5}$ & 2.6 & $1.6 \times 10^{-3}$ & 414 \\
\hline
\end{tabular}

Figure 7 shows the results of laboratory heating of a spherical implant of $2 \mathrm{~cm}$ diameter made of self-curing silicone impression mold material with $1 \mathrm{~mm}$ diameter steel balls added at the specified volume ratio $(4 \%, 9 \%$ and $19 \%)$. The Curie temperature of steel is very high $\left(\sim 770^{\circ} \mathrm{C}\right)$ so that thermoregulation at the desired target temperature does not occur with this ferromagnetic heat source. Instead, final temperature of the steel balls will depend on magnetic field strength which must be adjusted during treatment to maintain appropriate implant temperature. For a volume fraction of $19 \%$ ferromagnetic filler, it takes just over 2 minutes to increase the implant temperature by $10^{\circ} \mathrm{C}$ in a $500 \mathrm{~A} / \mathrm{m}$ field. Higher or lower volume fractions will affect the heating rate as shown in figure 7, or equivalent heating rates could be achieved by adjusting the magnetic field strength. Since the thermal conductivity of silicone is a little less than half that of tissue and orders of magnitude lower than the steel, the $1 \mathrm{~mm}$ diameter balls should be located no more than 1-2 $\mathrm{mm}$ apart to minimize variation in implant temperature between balls. A volume fill ratio of $19 \%$ or more will produce rapid heating with little temperature variation across the implant.

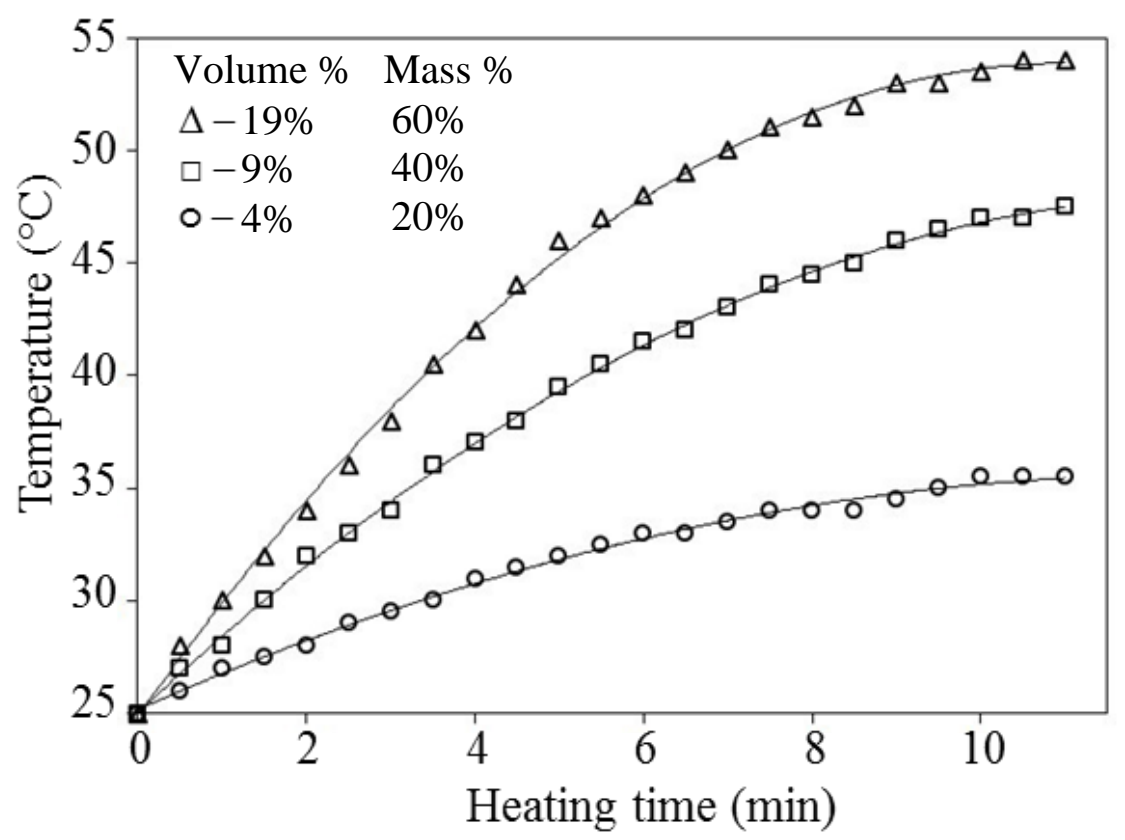

Figure 7 Experimental results of applying $20 \mathrm{~W}$ to a laboratory $100 \mathrm{KHz}$ magnetic induction heating system coupled to a $2 \mathrm{~cm}$ diameter implant filled with three different volume (mass) fractions of ferromagnetic steel balls distributed within the silicone base.

\section{Discussion}

The results of a 96 patient pilot study establish the clinical potential of a new multimodality treatment approach for laryngeal cancer. The treatment consists of combining partial larynx 
resection surgery with sequential HDR brachytherapy, which is delivered to the resection cavity from within a silicone gel implant that is formed intraoperatively to fit the tumor bed. All patients received preoperative external beam radiotherapy concurrently with systemic chemotherapy. In patients with tumor reduction from initial therapy, an HDR dose was delivered via afterloading catheters inserted into the tumor bed implant. As a consequence, this procedure allowed reduction in the resection volume and improved the likelihood of preserving organ function.

The excellent clinical results relate to patient selection as this study considers only the highly favorable patient group consisting of just 48 of the initial 96 patient group. Radiation Therapy Oncology Group (RTOG) 91-11 showed 5 year overall survival ranging from $53.8 \%$ to $58.1 \%$ for three different treatment protocols in patients with Stage III or IV glottic or supraglottic squamous cell cancers (Forastiere et al., 2013). The study considered in this work reports a much higher clinical response rate, with 5 year relapse free survival of $95.8 \%$. In the RTOG study, 5 year larynx preservation ranged from $65.8 \%$ to $83.6 \%$ for the three protocols, whereas the larynx was preserved in all but the two treatment failures $(95.8 \%)$ in the current study. While there are limitations in extrapolating results between different study populations, the findings suggest this approach may benefit a wider range of patients when combined with hyperthermia.

On critical review, the results obtained with this novel technique should be considered a demonstration of feasibility rather than proof of efficacy of this approach. First of all, the trial was conducted on a specially selected group of patients including only T3 tumors with clinically and radiographically negative cervical lymph nodes, and only in those patients whose tumor decreased after initial external beam radiotherapy delivered concurrently with systemic chemotherapy. These selection criteria may explain the high 5-year survival rate, which is not easily compared to previously published studies of organ preservation techniques for laryngeal cancer. Nevertheless, initial success with this method supports the feasibility of a new organ preservation regimen, at least in cases with intermediate risk laryngeal cancer.

This new clinical procedure was conceived and the first clinical trial performed in Kemerovo, Russia. One of the advantages of this method stems from its potential to be readily combined with intraoperative contact hyperthermia for additional improvement in patient outcomes. This type of hyperthermia is akin to ferromagnetic thermoseed hyperthermia except its aim is not to heat a large tumor as in previous studies (Mack et al., 1993, Stauffer et al., 1984a, Tucker et al., 2000, Brezovich et al., 1984), but rather just a thin shell $(\sim 5 \mathrm{~mm})$ of at-risk tissue surrounding a tumor resection cavity. Precise localization of treatment to just the tumor bed can be achieved using a custom fitting implant to deliver both brachytherapy and hyperthermia. In order to generate heat, we propose to distribute small $1 \mathrm{~mm}$ spherical ferromagnetic particles uniformly throughout the interior of a patient-customized silicone implant that fills the tumor resection cavity. This contrasts with the traditional use of ferromagnetic implant arrays which are highly invasive and require numerous 
closely spaced interstitial needles or catheters throughout an intact tumor volume (Chin and Stauffer, 1991, Stauffer et al., 1984b, Stauffer et al., 1984a, Mack et al., 1993, Tompkins et al., 1994). That multiple needle implant procedure is time intensive for the surgeon and painful for the patient, and if the spacing is increased from 1.0 towards $1.5 \mathrm{~cm}$ for clinical practicality, the ability to achieve homogenous heating within the target volume becomes compromised (Chin and Stauffer, 1991). The use of $1 \mathrm{~mm}$ ferromagnetic spheres packed close together within the implant allows uniform heating of tumor bed in contact with the essentially equi-temperature implant surface. This compares favorably with the extreme peaks and valleys of temperature found within a ferromagnetic seed implant array (Chin and Stauffer, 1991).

For practical use of this thermobrachytherapy approach, the surgical and brachytherapy aspects can remain the same as the clinical trial described above (Vasil'chenko et al., 2011), while adding a hyperthermia treatment immediately before or after the HDR brachytherapy. Target tissue temperatures may be controlled during treatment in one of two ways. Initially, to maintain the desired implant surface temperature sensors may be placed inside the implant catheters for continuous monitoring and feedback control of magnetic field strength. Eventually, the steel balls may be replaced with ferromagnetic balls that undergo their Curie point transition at a temperature established during initial clinical investigations to achieve sufficient thermal dose throughout the target volume. With a self-regulating Curie point implant, thermal treatments would be possible with or without temperature sensors for monitoring implant temperature during heating.

The effect of blood perfusion on temperature distribution was analyzed based on a wide range of muscle tissue properties $\left(0-6.2 \mathrm{~kg} / \mathrm{s} / \mathrm{m}^{3}\right)$ that is representative of most soft tissues in the human body (Jain and Wardhartley, 1984, Waterman et al., 1987). For the initially proposed $45^{\circ} \mathrm{C}$ implant surface temperature, the therapeutic penetration depth was estimated to be between $3.2-10 \mathrm{~mm}$ (figure 6a), which should provide the desired thermal boost to at-risk tissues for all but the highest perfusion rate. To accommodate use of this approach in highly perfused tumor bed, implant temperatures were recalculated (figure $6 \mathrm{~b}$ ) to ensure penetration of the desired minimum therapeutic temperature of $40^{\circ} \mathrm{C}$ out to at least $5 \mathrm{~mm}$ radial distance from the implant. In the case of high implant temperatures needed for high perfusion tissue, some overheating of 1-2 mm of target tissue immediately adjacent to the implant surface is likely. Slight overtreatment of at-risk tissue immediately adjacent to the implant is not an unexpected "toxicity" of brachytherapy implants. For sensitive tissue locations where this is a concern, the oncologist may limit temperatures to $45-46^{\circ} \mathrm{C}$ at the implant surface even for high perfusion cases, assuming that tissue perfusion will be reduced during treatment. Moreover, adding hyperthermia to brachytherapy may allow some reduction of radiation dose, potentially limiting radiation-related side effects.

The thermal dose is quantified in terms of CEM43, which stands for cumulative equivalent minutes at $43^{\circ} \mathrm{C}$. Considering the thermal dose delivered with the aforementioned approach, the 
maximum CEM43 dose in "normal tissue" at $r=5 \mathrm{~mm}$ from the implant is the same as the minimum CEM43 dose at the target periphery. The goal considered in figure 6 simulations is to cover the target with a minimum thermal dose of $40^{\circ} \mathrm{C}$ for $60 \mathrm{~min}$, which corresponds to a CEM43 of approximately 1 equivalent minute. Depending on the goal of the radiation oncologist, the maximum thermal dose to the target volume would be $45^{\circ} \mathrm{C}$ for $60 \mathrm{~min}$ (figure $6 \mathrm{a}$ ), which corresponds to a CEM43 of 240 equivalent minutes. However, if acceptable clinically, a much higher dose might be used adjacent to the implant surface to accommodate cases with very high blood perfusion. Regardless of perfusion level, the maximum CEM43 thermal dose expected in normal tissue at distances greater than $5 \mathrm{~mm}$ from the implant is about 1 equivalent minute.

Finally, we determined the required magnetic field to guarantee a minimum $40^{\circ} \mathrm{C}$ throughout the tumor bed target, yielding 163-414 A/m depending on heat removal from blood perfusion. As has been reported previously, this field is well tolerated clinically even in large patients, effectively coupling energy into implanted ferromagnetic seeds while minimizing undesired heating of normal tissues (Mack et al., 1993, Stauffer et al., 1994). In practice, the field strength should be determined for the worst case high perfusion scenario while using ferroseed materials that undergo their Curie point transition from magnetic to non-magnetic at the desired treatment temperature (Brezovich et al., 1984, Cetas et al., 1998, Kobayashi et al., 1986). Above this minimum threshold field strength, such ferroseeds will self-regulate temperature close to their inherent Curie point regardless of excess field, leading to more uniform tumor heating in a variable perfusion environment without the need to measure internal source temperatures or adjust power of the magnetic field. Moreover, the use of Curie point thermoregulating seeds maintains uniform temperatures within the implant even though the ferromagnetic balls are not in equal conditions, since the outer balls partially shield the inner ones such that they do not receive the same magnetic field.

According to our calculations, the estimated maximum required field strength of $H_{m} \leq 413 \mathrm{~A} / \mathrm{m}$ is about 50 times less than the intensity of the alternating magnetic fields required for magnetic fluid hyperthermia (Ivkov, 2013, Petryk et al., 2013). This simplifies the equipment for generating the magnetic field and effectively eliminates direct eddy current heating of normal neck tissues. This ensures the treatment will be safe and well-tolerated clinically, even better than previously reported clinical trials of ferromagnetic implant hyperthermia (Stea et al., 1990, Stea et al., 1994, Tucker et al., 2000, Mack et al., 1993). Although practical tumor bed implants will have considerably more complex shape than the simple spherical implant studied in this work, the ability to heat up to $10 \mathrm{~mm}$ radially around a large implant and the low field required to heat the implant demonstrate the potential for this hyperthermia approach. 


\section{Conclusions}

A new method for treatment of locally advanced head and neck tumors was applied to a preselected group of 48 male patients with stage T3N0M0 cancer of the larynx. The method involves organ-preserving surgery followed by high-dose-rate brachytherapy of the resection cavity wall delivered from within an intraoperatively formed custom silicone implant that fills the tumor bed. The implant also maintains position of regularly spaced brachytherapy catheters for several hours to deliver a post-operative brachytherapy dose to the tumor bed. In a selected group of patients with disease responsive to initial external beam radiation delivered concurrently with systemic chemotherapy, the 5-year recurrence-free survival rate was 95.8\%. Improvement in long term clinical outcome is anticipated in less favorable locally advanced head and neck cancers by adding local hyperthermia to the organ sparing surgery and brachytherapy. Experiments were conducted which confirm a theoretical analysis that demonstrates the feasibility of applying effective hyperthermia to at-risk tissues surrounding a resection cavity using inductive heating of ferromagnetic spheres dispersed uniformly within the polymeric matrix of a tumor bed implant, as a means to enhance brachytherapy response.

\section{Acknowledgements}

The authors wish to acknowledge the support of the institutions involved in these studies. The authors alone are responsible for the content and writing of the paper.

\section{References}

Al-Bataineh O, Jenne J \& Huber P 2011. Clinical and future applications of high intensity focused ultrasound in cancer. Cancer Treat Rev.

Amichetti M, Graiff C, Fellin G, Pani G, Bolner A, Maluta S \& Valdagni R 1993. Cisplatin, hyperthermia, and radiation (trimodal therapy) in patients with locally advanced head and neck tumors: A phase $\mathrm{i}-\mathrm{ii}$ study. International Journal of Radiation Oncology Biology Physics, 26, 801-807.

Arcangeli G, Lombardini PP, Lovisolo GA, Marsiglia G \& Piattelli M 1984. Focusing of $915 \mathrm{mhz}$ electromagnetic power on deep human tissues: A mathematical model study. IEEE Trans Biomed Eng, 31, 47-52.

Atkinson WJ, Brezovich IA \& Chakraborty DP 1984. Usable frequencies in hyperthermia with thermal seeds. IEEE Trans Biomed Eng, 31, 70-5.

Brezovich IA, Atkinson WJ \& Chakraborty DP 1984. Temperature distributions in tumor models heated by self-regulating nickel-copper alloy thermoseeds. Medical Physics, 11, 145-52.

Burton CV, Hill M \& Walker AE 1971. The rf thermoseed--a thermally self-regulating implant for the production of brain lesions. IEEE Transactions on Biomedical Engineering, 18, 104-109.

Canters RA, Wust P, Bakker JF \& Van Rhoon GC 2009. A literature survey on indicators for characterisation and optimisation of sar distributions in deep hyperthermia, a plea for standardisation. Int $J$ Hyperthermia, 25, 593-608.

Cetas TC, Gross EJ \& Contractor Y 1998. A ferrite core/metallic sheath thermoseed for interstitial thermal therapies. IEEE Transactions on Biomedical Engineering, 45, 68-77. 
Chen D, Xia R, Chen X, Shafirstein G, Corry PM, Griffin RJ, Penagaricano JA, Tulunay-Ugur OE \& Moros EG 2011. Sonoknife: Feasibility of a line-focused ultrasound device for thermal ablation therapy. Med Phys, 38, 4372-85.

Chin RB \& Stauffer PR 1991. Treatment planning for ferromagnetic seed heating. Int J Radiat Oncol Biol Phys, 21, 431-9.

Datta NR, Puric E, Klingbiel D, Gomez S \& Bodis S 2016a. Hyperthermia and radiation therapy in locoregional recurrent breast cancers: A systematic review and meta-analysis. Int J Radiat Oncol Biol Phys, 94, 1073-87.

Datta NR, Rogers S, Ordonez SG, Puric E \& Bodis S 2016b. Hyperthermia and radiotherapy in the management of head and neck cancers: A systematic review and meta-analysis. Int J Hyperthermia, 32, 31-40.

Dewhirst M, Stauffer P, Das S, Craciunescu O \& Vujaskovic Z 2015. Hyperthermia. In: LI G \& Je T (eds.) Clinical Radiation Oncology 4th Ed. Philadelphia: Elsevier.

Falk MH \& Issels RD 2001. Hyperthermia in oncology. Int J Hyperthermia, 17, 1-18.

Fatehi D \& Van Rhoon GC 2008. Sar characteristics of the sigma-60-ellipse applicator. International Journal of Hyperthermia, 24, 347-56.

Forastiere AA, Zhang Q, Weber RS, Maor MH, Goepfert H, Pajak TF, Morrison W, Glisson B, Trotti A, Ridge $\mathrm{JA}$, et al. 2013. Long-term results of rtog 91-11: A comparison of three nonsurgical treatment strategies to preserve the larynx in patients with locally advanced larynx cancer. J Clin Oncol, 31, 845-52.

Gross EJ, Cetas TC, Stauffer PR, Liu RL \& Lumori ML 1990. Experimental assessment of phased-array heating of neck tumours. Int J Hyperthermia, 6, 453-74.

Haar GT \& Coussios C 2007. High intensity focused ultrasound: Past, present and future. Int J Hyperthermia, 23, 85-7.

Hasgall PA, Di Gennaro F, Neufeld E, Gosselin MC, Payne D, Klingenböck A \& Kuster N January 13th, 2015. It'is database for thermal and electromagnetic parameters of biological tissues, version 2.6.

Holsinger FC 2008. Swing of the pendulum: Optimizing functional outcomes in larynx cancer. Curr Oncol Rep, 10, 170-5.

Hurwitz M \& Stauffer P 2014. Hyperthermia, radiation and chemotherapy: The role of heat in multidisciplinary cancer care. Semin Oncol, 41, 714-29.

Hurwitz MD, Ghanouni P, Kanaev SV, lozeffi D, Gianfelice D, Fennessy FM, Kuten A, Meyer JE, Leblang SD, Roberts A, et al. 2014. Magnetic resonance-guided focused ultrasound for patients with painful bone metastases: Phase iii trial results. J Natl Cancer Inst, 106.

Issels RD, Lindner LH, Verweij J, Wust P, Reichardt P, Schem BC, Abdel-Rahman S, Daugaard S, Salat C, Wendtner CM, et al. 2010. Neo-adjuvant chemotherapy alone or with regional hyperthermia for localised high-risk soft-tissue sarcoma: A randomised phase 3 multicentre study. Lancet Oncol.

Ivkov R 2013. Magnetic nanoparticle hyperthermia: A new frontier in biology and medicine? Int J Hyperthermia, 29, 703-5.

Jain RK \& Wardhartley K 1984. Tumor blood-flow - characterization, modifications, and role in hyperthermia. leee Transactions on Sonics and Ultrasonics, 31, 504-526.

Kobayashi T, Kida Y, Tanaka T, Kageyama N \& Kobayashi H 1986. Magnetic induction hyperthermia for brain tumor using ferromagnetic implant with low curie temperature. I. Experimental study. Journal of Neuro-Oncology, 4, 175-181.

Kouloulias V, Triantopoulou S, Vrouvas J, Gennatas K, Ouzounoglou N, Kouvaris J, Karaiskos P, Aggelakis P, Antypas C, Zygogianni A, et al. 2014. Combined chemoradiotherapy with local microwave hyperthermia for treatment of $\mathrm{t} 3 \mathrm{n} 0$ laryngeal carcinoma: A retrospective study with long-term follow-up. Acta Otorhinolaryngol Ital., 34, 167-73.

Mack CF, Stea B, Kittelson JM, Shimm DS, Sneed PK, Phillips TL, Swift PS, Luk K, Stauffer PR, Chan KW, et al. 1993. Interstitial thermoradiotherapy with ferromagnetic implants for locally advanced and recurrent neoplasms. International Journal of Radiation Oncology Biology Physics, 27, 109-115.

Obinata K, Ohmori K, Shirato H \& Nakamura M 2007. Experience of high-dose-rate brachytherapy for head and neck cancer treated by a customized intraoral mold technique. Radiat Med, 25, 181-6.

Osintsev AM, Majtakov AL, Vasil'chenko IL, Vinogradov VM \& Rynk VV. 2013. Method for local induction heating of biological tissues. Russia patent application RU 2497489 C1. 
Overgaard J, Gonzales Gonzales D, Hulshof MCCH, Arcangeli G, Dahl O, Mella O \& Bentzen SM 1996. Hyperthermia as an adjuvant to radiation therapy of recurrent or metastatic malignant melanoma. A multicentre randomized trial by the european society for hyperthermia oncology. International Journal of Hyperthermia, 12, 3-20.

Paulides MM, Bakker JF, Linthorst M, Van Der Zee J, Rijnen Z, Neufeld E, Pattynama PM, Jansen PP, Levendag PC \& Van Rhoon GC 2010. The clinical feasibility of deep hyperthermia treatment in the head and neck: New challenges for positioning and temperature measurement. Phys Med Biol, 55, 2465-80.

Paulides MM, Bakker JF, Neufeld E, Van Der Zee J, Jansen PP, Levendag PC \& Van Rhoon GC 2007a. The hypercollar: A novel applicator for hyperthermia in the head and neck. International Journal of Hyperthermia, 23, 567-76.

Paulides MM, Bakker JF, Zwamborn AP \& Van Rhoon GC 2007b. A head and neck hyperthermia applicator: Theoretical antenna array design. International Journal of Hyperthermia, 23, 59-67.

Pennes HH 1948. Analysis of tissue and arterial blood temperatures in the resting human forearm. Journal of Applied Physiology, 1, 93-122.

Petryk AA, Giustini AJ, Gottesman RE, Kaufman PA \& Hoopes PJ 2013. Magnetic nanoparticle hyperthermia enhancement of cisplatin chemotherapy cancer treatment. Int J Hyperthermia, 29, 845-51.

Rodrigues D, Pereira J, Limão-Vieira P, Stauffer P \& Maccarini P 2013. Study of the one dimensional and transient bioheat transfer equation: Multilayer solution development and applications. International Journal of Heat and Mass Transfer, 62, 153-162.

Rudolph E, Dyckhoff G, Becher H, Dietz A \& Ramroth H 2011. Effects of tumour stage, comorbidity and therapy on survival of laryngeal cancer patients: A systematic review and a meta-analysis. Eur Arch Otorhinolaryngol, 268, 165-79.

Sekins KM, Lehmann JF, Esselman P, Dundore D, Emery AF, Delateur BJ \& Nelp WB 1984. Local muscle blood-flow and temperature responses to $915 \mathrm{mhz}$ diathermy as simultaneously measured and numerically predicted. Archives of Physical Medicine and Rehabilitation, 65, 1-7.

Sneed PK, Stauffer PR, Mcdermott MW, Diederich CJ, Lamborn KR, Prados MD, Chang S, Weaver KA, Spry L, Malec MK, et al. 1998. Survival benefit of hyperthermia in a prospective randomized trial of brachytherapy boost +/- hyperthermia for glioblastoma multiforme. Int J Radiat Oncol Biol Phys, 40, 287-95.

Sperry SM, Rassekh CH, Laccourreye O \& Weinstein GS 2013. Supracricoid partial laryngectomy for primary and recurrent laryngeal cancer. JAMA Otolaryngol Head Neck Surg, 139, 1226-35.

Stauffer PR, Cetas TC, Fletcher AM, Deyoung DW, Dewhirst MW, Oleson JR \& Roemer RB 1984a. Observations on the use of ferromagnetic implants for inducing hyperthermia. IEEE Trans Biomed Eng, 31, 76-90.

Stauffer PR, Cetas TC \& Jones RC 1984b. Magnetic induction heating of ferromagnetic implants for inducing localized hyperthermia in deep-seated tumors. IEEE Trans Biomed Eng, 31, 235-51.

Stauffer PR, Diederich CJ \& Seegenschmiedt MH 1995. Interstitial heating technologies. In: Seegenschmiedt $\mathrm{MH}$, Fessenden P \& Vernon CC (eds.) Thermoradiotherapy and thermochemotherapy: Volume 1, biology, physiology and physics. Berlin, New York: Springer-Verlag.

Stauffer PR, Sneed PK, Hashemi H \& Phillips TL 1994. Practical induction heating coil designs for clinical hyperthermia with ferromagnetic implants. IEEE Trans Biomed Eng, 41, 17-28.

Stea B, Cetas TC, Cassady JR, Guthkelch AN, lacono R, Lulu B, Lutz W, Obbens E, Rossman K, Seeger J, et al. 1990. Interstitial thermoradiotherapy of brain tumors: Preliminary results of a phase i clinical trial. International Journal of Radiation Oncology Biology Physics, 19, 1463-1471.

Stea B, Rossman K, Kittelson J, Shetter A, Hamilton A \& Cassady JR 1994. Interstitial irradiation versus interstitial thermoradiotherapy for supratentorial malignant gliomas: A comparative survival analysis. International Journal of Radiation Oncology Biology Physics, 30, 591-600.

Tempany CM, Mcdannold NJ, Hynynen K \& Jolesz FA 2011. Focused ultrasound surgery in oncology: Overview and principles. Radiology, 259, 39-56.

Togni P, Rijnen Z, Numan WC, Verhaart RF, Bakker JF, Van Rhoon GC \& Paulides MM 2013. Electromagnetic redesign of the hypercollar applicator: Toward improved deep local head-and-neck hyperthermia. Phys Med Biol, 58, 5997-6009.

Tompkins DT, Vanderby R, Klein SA, Beckman WA, Steeves RA \& Paliwal BR 1994. Effect of interseed spacing, tissue perfusion, thermoseed temperatures and catheters in ferromagnetic hyperthermia: 
Results from simulations using finite element models of thermoseeds and catheters. IEEE Trans Biomed Eng, 41, 975-85.

Tucker RD, Huidobro C, Larson T \& Platz CE 2000. Use of permanent interstitial temperature self-regulating rods for ablation of prostate cancer. J Endourol, 14, 511-7.

Valdagni R \& Amichetti M 1994. Report of long-term follow-up in a randomized trial comparing radiation therapy and radiation therapy plus hyperthermia to metastatic lymph nodes in stage iv head and neck patients. International Journal of Radiation Oncology Biology Physics, 28, 163-169.

Van Rhoon GC, Van Der Heuvel DJ, Ameziane A, Rietveld PJ, Volenec K \& Van Der Zee J 2003. Characterization of the sar-distribution of the sigma-60 applicator for regional hyperthermia using a schottky diode sheet. International Journal of Hyperthermia, 19, 642-54.

Vasil'chenko IL, Vinogradov VM, Pastushenko DA, Osintsev AM, Maitakov AL, Rynk VV \& Vasil'chenko NV 2013. [use of local induced hyperthermia in the treatment of malignant tumors]. Vopr Onkol, 59, 84-9.

Vasil'chenko IL, Vinogradov VM, Pastushenko DA, Samsonova NN \& ludin AL 2011. [first experience with intrasurgical brachytherapy in the combined treatment for locally advanced laryngeal cancer]. Vopr Onkol, 57, 232-5.

Vasil'chenko IL, Pastushenko DA, Kuznetsova TA, Polikarpov AF, Magarill JA, Mal'tsev AA, Judin AL, Cherno SV \& Shegaj TS. 2008. Method for treating malignant tumors of larynx and laryngopharynx. Russia patent application RU 2322199 C1.

Waterman FM, Nerlinger RE, Moylan DJ, 3rd \& Leeper DB 1987. Response of human tumor blood flow to local hyperthermia. International Journal of Radiation Oncology Biology Physics, 13, 75-82.

Wilkie MD, Lightbody KA, Lythgoe D, Tandon S, Lancaster J \& Jones TM 2015. Transoral laser microsurgery for early and moderately advanced laryngeal cancers: Outcomes from a single centralised united kingdom centre. Eur Arch Otorhinolaryngol, 272, 695-704. 